\title{
Rethinking about Tubulocystic Carcinoma of the Kidney after Taking into Account the Existence of Tubulocystic Chromophobe Renal Carcinoma
}

\author{
Tübülokistik Patternde Kromofob Renal Karsinom Ertesinde Tübülokistik Renal Hücreli \\ Karsinoma Farklı Bakış
}

To the Editor,

Chromophobe renal cell carcinoma (ChRCC) is a variant of RCC with certain histological, immunohistological and cytogenetic characteristics. It is believed to arise from the intercalated cells of distal tubules and has a more favourable prognosis than other more common subtypes, clear cell and papillary RCC. Microscopically, neoplastic cells of ChRCC are typically arranged in solid sheets, trabeculae, sometimes acini. Areas of tubulocystic morphology have been reported rarely (1). But a prominent multicystic presentation is very unusual.

Recently, I have seen a case of chromophobe renal cell carcinoma composed entirely of tubulocystic architecture. The patient was a 48-year-old female without a significant past medical history, who presented with the complaint of flank pain on the left. An abdominal CT scan showed a contrast-enhancing mass located on the upper pole of the left kidney. There was also a $1.2 \mathrm{~cm}$ renal stone in the lower calyceal system of the same organ. She underwent a partial nephrectomy and nephrolithotomy operation. The tumor was a $7 \times 6 \times 5.5 \mathrm{~cm}$ well-circumscribed partly exophytic lesion, had a spongy appearance at the cut surface, and consisted of innumerable small $0.1-1 \mathrm{~cm}$ cysts macroscopically without a solid component (Figure 1 $\mathrm{A}, \mathrm{B})$. Under the microscope, the neoplasm was composed of tubules and cystic structures of markedly variable size, separated by thin septa and had a look that was reminiscent of a spider web at low magnification (Figure 2). Tubules and cysts were lined by a single layer of cuboidal or columnar epithelial cells with modest to abundant amounts of eosinophilic cytoplasm. Neoplastic cells carried the characteristic features of ChRCC such as raisinoid hyperchromatic nuclei and perinuclear halo (Figure 3A,B). There were scattered pale cells with reticular cytoplasm. Immunohistochemistry supported chromophobe subtype by showing diffuse cytokeratin 7 and CD117 expression (Figure 4A,B). Vimentin and CD10 antigen were negative. Necrosis was not identified. The lesion was grade I/III ChRCC according to novel grading scheme suggested by Paner et al. (2).

Classically, ChRCC is a solid mass developing in the renal parenchyma. While cystic change has occasionally been mentioned in ChRCC, this degree of macroscopic cyst formation is very unusual and to my knowledge has not previously been described. Such a tumor should be distinguished from other renal cystic neoplasia and the first entity in the list of differential diagnosis most probably will be tubulocystic renal carcinoma (TCRC) (3). In fact, coming across with the current case may possibly evoke pathologists to question the real existence of tubulocystic renal carcinoma as a distinct entity. The discussion about the cell of origin of TCRC still continues. MacLennan, et al hypothesized initially that they were low grade variants of collecting duct tumors, with support from immunopositivity for 34ßE12 and Ulex Europeus antigen-1 similar to those of classic collecting duct carcinoma (4). Afterwards, 5 tumors from their original series of 13 "low grade collecting duct carcinomas" were re-classified as mucinous tubular and spindle cell renal cell carcinoma (5). Other investigators have reported that TCRC is different from classic collecting duct carcinoma at the molecular level (6). Some have shown a relationship or coexistence with papillary renal cell carcinoma (7). The present case, documenting that they can be of the chromophobe type as well, seems to point that TCRC may not be a distinct entity with an unknown histogenesis, but rather a peculiar tumor pattern that can be seen in various low grade renal carcinoma subtypes. That

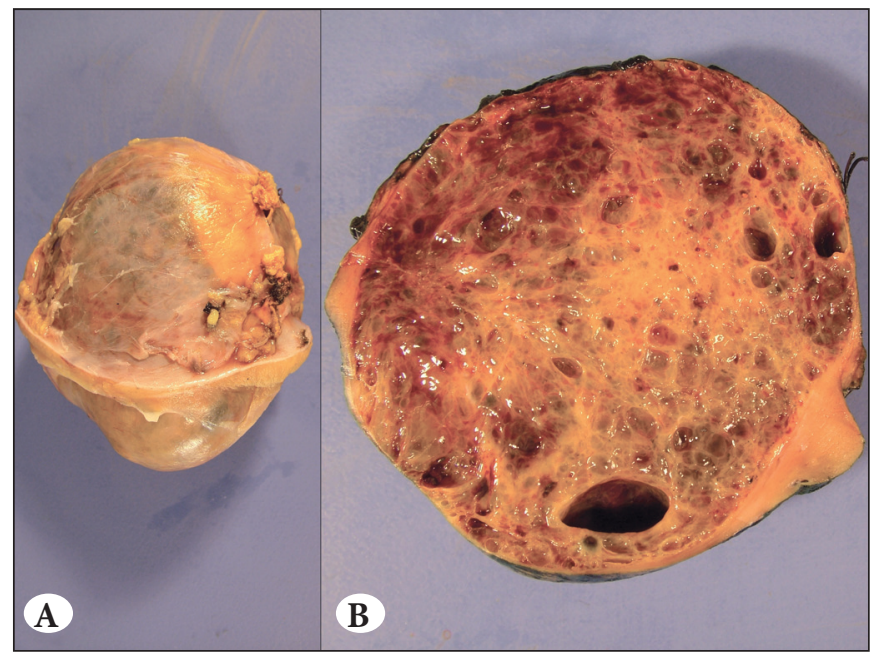

Figure 1: A) Partial nephrectomy specimen B) with bubble-wrap like cut surface macroscopically due to multi-cystic constitution of the tumor. 


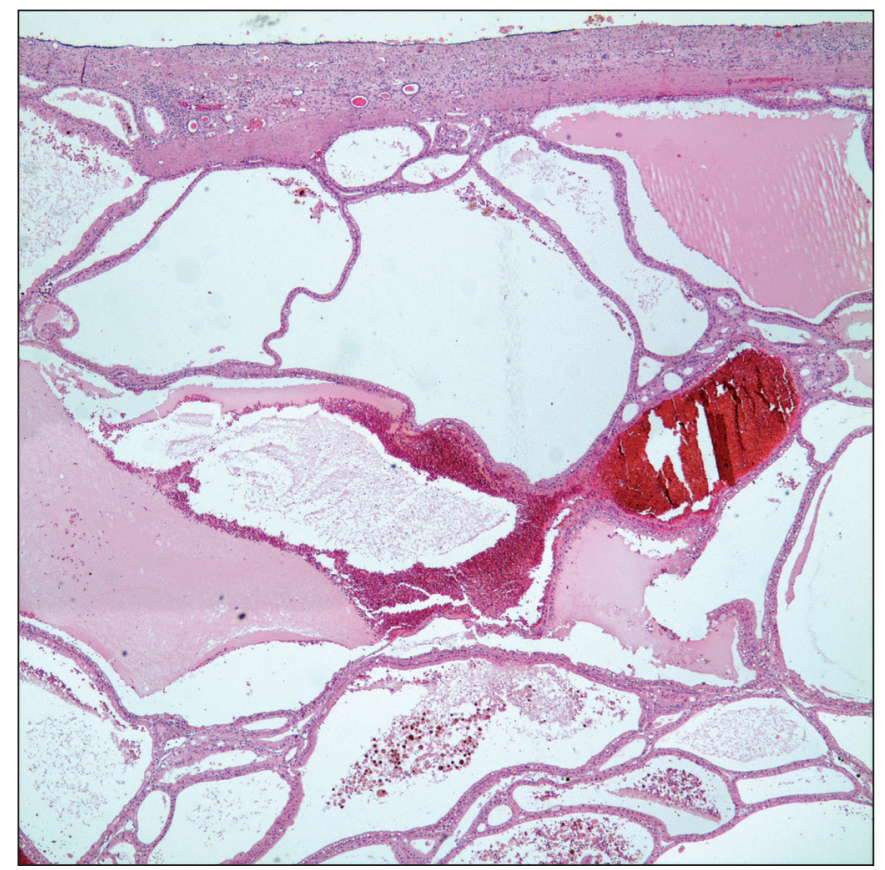

Figure 2: Numerous cysts, some containing pink secretions or erythrocytes (H\&E; $\mathrm{x} 40)$.

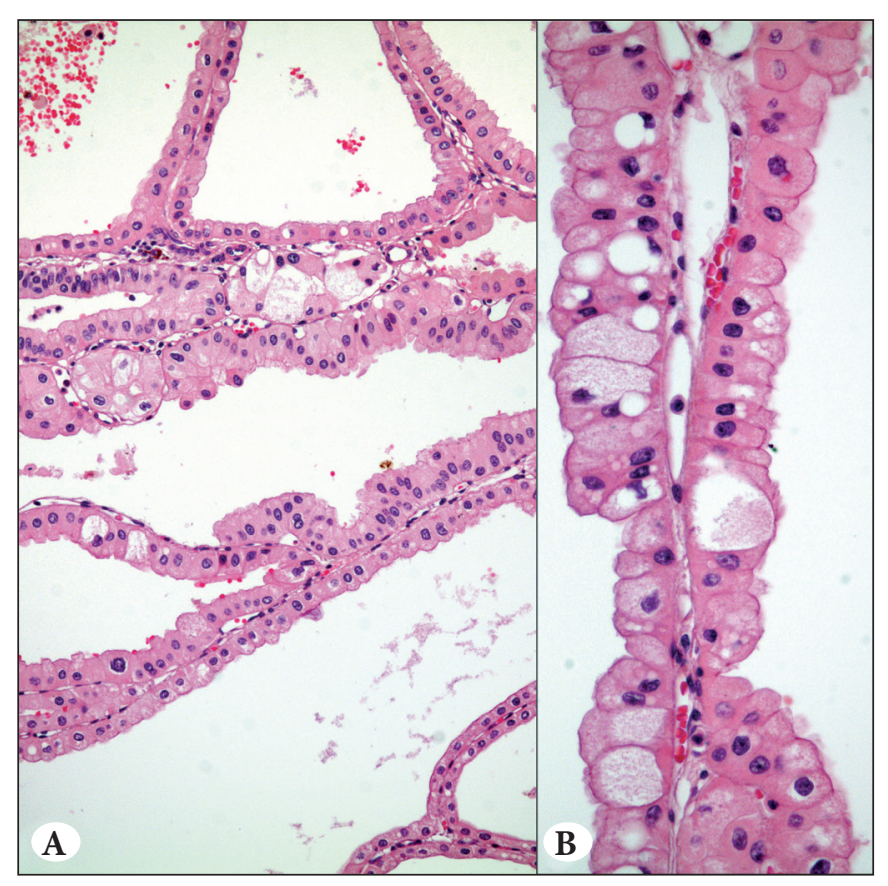

Figure 3: Neoplastic cells carry the typical features of chromophobe renal cell carcinoma. A) H\&E; x200. B) H\&E; x400).

is similar to sarcomatoid RCC, which is not considered as a separate variant anymore and is known to occur in any RCC. Is there still a subgroup of TCRC that does not fit to any recognized RCC subtypes? Probably yes and this is because there are still unclassified types of renal cell

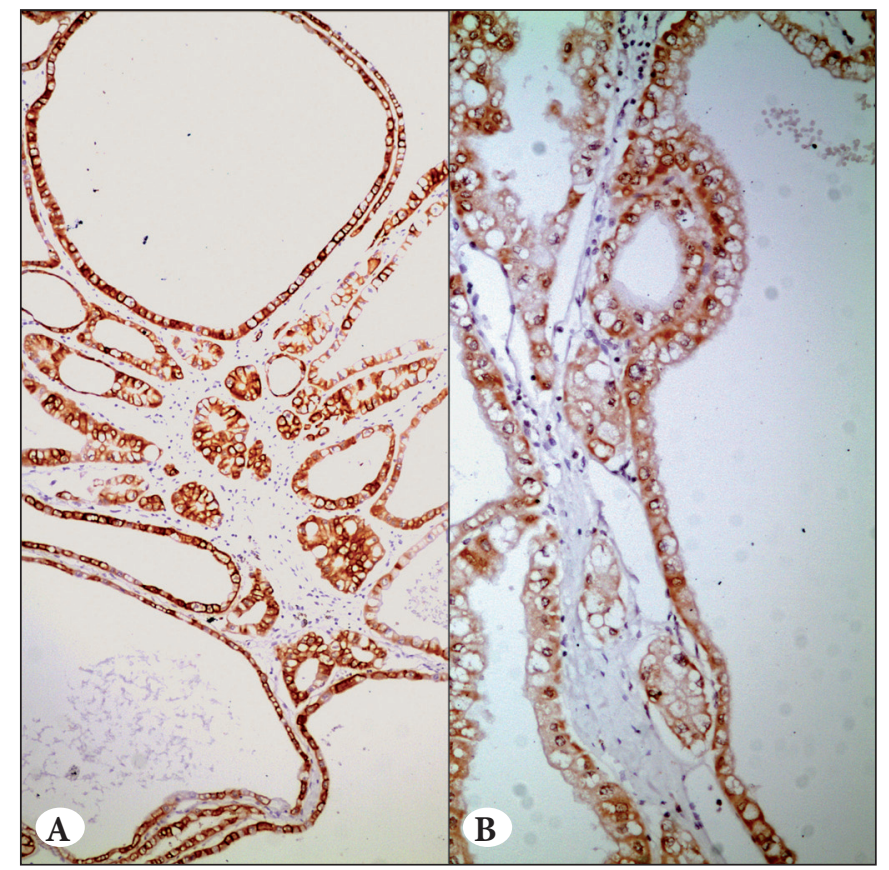

Figure 4: A) Immunohistochemical expression of cytokeratin 7 (CK 7; x100) and B) CD117 in tumor cells (CD117; x200).

carcinoma that may present in tubulocystic morphology in addition to the various other patterns. Yet, the clarification of the issue awaits more cases to be reported and discovery of the detailed genetic alterations involving wide spectrum renal cell tumors. Other tumor types known to present tubulocystic pattern are oncocytoma, cystic nephroma, multilocular cystic RCC and acquired cystic diseaseassociated RCC $(8,9)$.

In conclusion, the current case proves that tubulocytic morphology is a pattern that is shared by many different subtypes of renal neoplasia. Chromphobe RCC is not an exemption and may consist even entirely of macroscopic cysts and tubules, and must be included in the differential diagnosis of renal tumors with a tubulocystic pattern. Many renal neoplasia with tubulocystic architecture have been recognized only recently. Distinction between these is essential, as their biologic behavior and potential therapeutic options may be distinct. Careful focusing on the cyto-histologic characteristics will allow us to reach the accurate diagnosis in most, although occasionally immunohistochemistry and genetic analysis may be required.

\section{Dilek ERTOY BAYDAR}

Hacettepe University, School of Medicine, Department of Pathology, ANKARA, TURKEY

E-mail: dertoy@hacettepe.edu.tr

Phone: +9031230515 55 


\section{REFERENCES}

1. Przybycin CG, Cronin AM, Darvishian F, Gopalan A, Al-Ahmadie HA, Fine SW, Chen YB, Bernstein M, Russo P, Reuter VE, Tickoo SK. Chromophobe renal cell carcinoma: A clinicopathologic study of 203 tumors in 200 patients with primary resection at a single institution. Am J Surg Pathol. 2011;35:962-70.

2. Paner GP, Amin MB, Alvarado-Cabrero I, Young AN, Stricker $\mathrm{HJ}$, Moch H, Lyles RH. A novel tumor grading scheme for chromophobe renal cell carcinoma: Prognostic utility and comparison with Fuhrman nuclear grade. Am J Surg Pathol. 2010;34:1233-40.

3. Amin MB, MacLennan GT, Gupta R, Grignon D, Paraf F, Vieillefond A, Paner GP, Stovsky M, Young AN, Srigley JR, Cheville JC. Tubulocystic carcinoma of the kidney: Clinicopathologic analysis of 31 cases of a distinctive rare subtype of renal cell carcinoma. Am J Surg Pathol. 2009;33:384-92.

4. MacLennan GT, Farrow GM, Bostwick DG. Low-grade collecting duct carcinoma of the kidney: Report of 13 cases of low-grade mucinous tubulocystic renal carcinoma of possible collecting duct origin. Urology. 1997;50:679-84.
5. MacLennan GT, Bostwick DG. Tubulocystic carcinoma, mucinous tubular and spindle cell carcinoma, and other recently described rare renal tumors. Clin Lab Med. 2005;25:393-416.

6. Osunkoya AO, Young AN, Wang W, Netto GJ, Epstein JI. Comparison of gene expression profiles in tubulocystic carcinoma and collecting duct carcinoma of the kidney. Am J Surg Pathol. 2009;33:1103-6.

7. Zhou M, Yang XJ, Lopez JI, Shah RB, Hes O, Shen SS, Li R, Yang Y, Lin F, Elson P, Sercia L, Magi-Galluzzi C, Tubbs R. Renal tubulocystic carcinoma is closely related to papillary renal cell carcinoma: implications for pathologic classification. Am J Surg Pathol. 2009;33:1840-9.

8. Amin MB, Crotty TB, Tickoo SK, Farrow GM. Renal oncocytoma: A reappraisal of morphologic features with clinicopathologic findings in 80 cases. Am J Surg Pathol. 1997;21:1-12.

9. Moch H. Cystic renal neoplasms. New entities and molecular findings. Pathologe. 2010;31 (Suppl 2):239-43. 